\title{
Using Concepts of CSCW to Validate Requirements Elicited for a Brazilian Geographic Information System
}

\author{
Danilo Sousa, Ana Siravenha, Damares de Resende, Reginaldo Filho, and Evaldo Pelaes
}

\begin{abstract}
This work is based on the connection between two important and growing fields in computing: Computer-Supported Cooperative Work (CSCW) and Geographic Information Systems (GIS). In this kind of system is important the concept of teamwork, due to the complexity and size of the projects underway around the world, where there may be situations where users need to access, modify and share spatial information in real time from different geographical locations, and also perform classifications, georeferencing and other activities synchronously. In the study summarized in this paper, was conducted a process of requirements engineering about the collaborative work in the TerraAmazon system, a multiuser workspace, developed with the open source geoprocessing library called Terralib, used in major important projects of urban and environmental research institutions, like the National Institute for Space Research (INPE). With regards to the requirements elicitation technique, it was made a kind of half-open interview with introspection and discussion of scenarios with photo interpreters (potential users) from INPE (The Amazon Regional Center) and Brazilian Enterprise for Agricultural Research (EMBRAPA). The requirements are validated and solutions are proposed using important concepts in CSCW, like awareness, coordinators and communicators. Finally, the conclusions are presented.
\end{abstract}

Index Terms-Computer-supported cooperative work, geographic information systems, groupware, TerraAmazon.

\section{INTRODUCTION}

Geographic Information Systems (GIS) are systems developed to manipulate georeferenced data, allowing the user to compare and analyze data faster than other traditional search methods. GIS allows create maps, models, queries of a huge amount of data over an unique database and are designed to support some specific requirements as demographic forecast, urban and mobility planning, environmental resources analysis and so on [1].

Implementing and using technology involves complex socio-technical challenges and the Computer Supported Cooperative Work (CSCW) field has made a contribution in mapping out the complexities of coordinating daily activities, understanding social interaction and the design, development and evaluation of technical systems supporting social interaction in teams and communities [2], [3]. Designing a CSCW system is not only about designing technical system, but also about shaping the social system around [3].

Manuscript received August 24, 2013; revised December 16, 2013. This work was supported by the Amazon Research Foundation/Vale S/A [Grant number 021/2010]; and the National Council of Technological and Scientific Development [grant number 142404/2011-0].

The authors are with the Technological Institute, Federal University of Para, Brazil (e-mail: danilofrazao@ufpa.br, siravenha@ufpa.br, damares.resende@itec.ufpa.br, pelaes@ufpa.br).
The CSCW uses computational technologies to assist groupware activities, and in field of GIS interest, aims the work efficiency, reducing the time consuming and the activities costs, increasing results quality, where groupware complex projects will be impractical without the computational support.

Collaborative GIS was firstly developed by [4]. In Strabo project was used geographic summaries to allow decision makers to access their position relative to others in the group.

In the 1990s, was developed an important GIS with groupware support, the GroupArc [5] that, in a distributed workspace, offers the awareness (one user can realize what the other users are doing in the same project and which activities they complete). Furthermore, it offers a sort of resources to real-time shared visualization, mainly in maps where two users can analyze one same scene at the same time with different tools [6].

In [7] was described the Active Response GIS (AR/GIS), an integrated system which combined GIS and electronic meeting software in order to improve the efficiency of land-resource deliberations, beyond offers land managers a means to interact more closely with geographic data.

Awareness, is the key-point in this work, and can be understood as the situation to be observed on a project, showing the state and the relationship among users within a group [8] and is one of the core concepts in groupware according [3]. In a project where the social interaction is required to spread and capture information to/from experts, awareness becomes a concurrent process that expands the demand for easy ways to access this information, standardized and problem-oriented.

A lot of papers combine GIS applications and awareness to integrate high level information in one effective system. In [9], is discussed one approach to analyze theoretical problems derived from GIS based situation awareness (SAW)solutions, including a case study for resolving maritime search situations GIS-based. Another maritime application was proposed by [10]. Having worked with US Coast Guard, they developed a waterway visual surveillance system for maritime awareness (GIS-enabled maritime awareness system - GMAS). It was designed a temporal difference algorithm based on active zone (ETD-AZ) to detect waterway moving objects - container ships, commercial vessels, small vessels, etc - with reduction of noises caused by winds, clouds, and waves in the near-view fields. In their tests was detected 89 of 94 waterway moving objects $(5.3 \%$ false negative rate and false positive rate of $4.0 \%$ ) and when focusing only on vessels, were detected 78 of 79 moving vessels with a $1.3 \%$ false negative rate.

The use of awareness in GIS applications for disasters management aims to explore the lack of mass participation. In [11] is highlighted the importance of intelligent mapping 
through analysis and data sharing for the design of an awareness program, that if implemented, would result in a proper dosage of awareness and caution to the general public, which in turn would help the activities of disaster management.

This article aims to exhibit a requirements engineering process for a real and operational GIS application. The purpose is to ripen the use of the Brazilian system called TerraAmazon using the concepts of CSCW to plan a more effective multiuser interface. Thus, the work is presented as follows: on the Section II in presented the TerraAmazon, the studied GIS; on Section III are shown the methods applied during the requirements elicitation (the practice of collecting the requirements of a system from users, customers and other stakeholders); followed by the Section IV, that exposes the most important system aspects in its current version, the requirements obtained and its validation based on $\mathrm{CSCW}$ concepts; finally, the last Section (Section V) summarizes the study and exposes the future expectations for this work.

\section{THE TERRAAMAZON SYSTEM}

The TerraAmazon ${ }^{1}$ is a Brazilian project, created in 2005 by the Foundation for Science, Technology and Space Applications (FUNCATE) and widely used by the Brazilian institute for space research (National Institute for Space Research - INPE), for spatial data manipulation based on the geospatial library Terra Lib [12]. This system realizes spatial operations in a multiuser workspace in which concurrent access can edit an unique database, tied to constraint rules and topology.

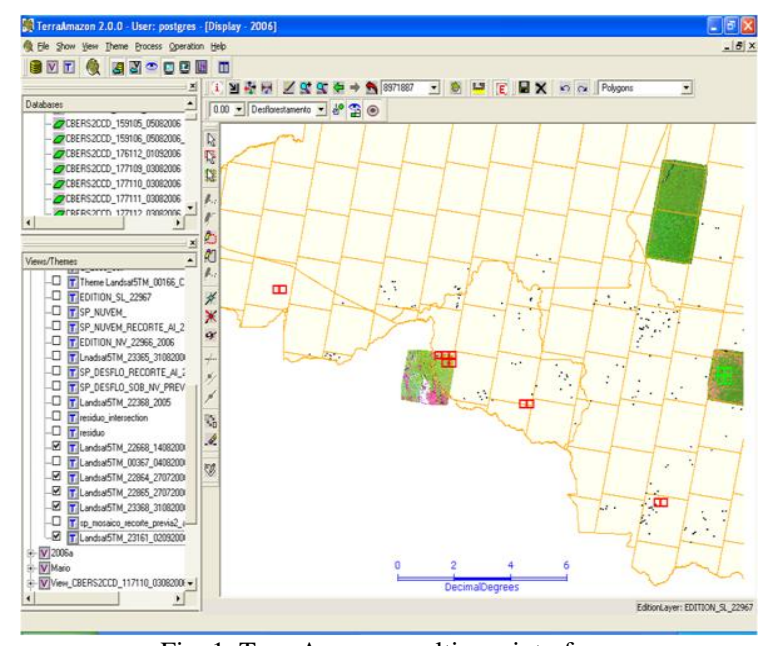

Fig. 1. TerraAmazon multiuser interface.

The Fig. 1 shows one screen of TerraAmazon. It is important to note the concurrent control over the cells at the moment of screen capture: the red cells are used by another user and a priori, unapproachable to the current user; the green cells are used by the present user; unmarked cells are available to classification. The system cells access control will be explored on next section.

There is on TerraAmazon a hierarchical level for projects development, with a sort of different levels of privilege [13]:

- Database administrator - can create, handle and delete the

${ }^{1}$ http://www3.funcate.org.br/geo//available/wiki-v01-TerraAmazon/pmw iki.php/Main/Home database. Defines the access constraints and create the topological relationship among geometrical features and its alpha-numeric information;

- Auditor - is capable of realize edition and information validation within the database;

- Interpreter - is the ordinary user, can use the GIS for extract information from analyzed images.

The Table I summarizes the permission offered to these kinds of users.

TABLE I: USER ACCESS CONTROL ON TERRAAMAZON

\begin{tabular}{llll}
\hline \hline \multirow{2}{*}{ User } & $\begin{array}{l}\text { Create database and } \\
\text { other administrative } \\
\text { activities }\end{array}$ & Interpretation & Auditing \\
\hline Administrator & Yes & No & No \\
Auditor & No & No & Yes \\
Interpreter & No & Yes & No \\
\hline \hline
\end{tabular}

\section{Methodology}

\section{A. Features of the Studied Interface}

The requirements elicitation was made in one of most important Brazilian institutions about urban and environmental monitoring by remote sensory: the National Institute for Space Research - INPE ${ }^{2}$. This institute was created at 1970 s decade in order to become a national and international reference in space and earth environment, fostering knowledge, attending and anticipating demands on Brazilian society life quality progress.

Specifically, the queries was made at Amazon Regional Center (INPE-CRA), located at the city of Belem, Para state. The activities of CRA involve research and scientific development becoming a world reference center in the monitoring of tropical forests, and it was chosen because it has the capability to expose the real requirements of the collaborative tools for GIS optimization.

It was also interviewed researchers from INPE relative institution, the Brazilian Agricultural Research Company

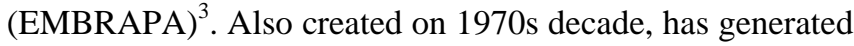
and recommended more than nine thousand technologies for Brazilian agriculture, reduced production costs and helped Brazil to increase the offer of food while, at the same time, conserving natural resources and the environment and diminishing external dependence on technologies, basic products and genetic materials.

It was interviewees 07 TerraAmazon users, 03 from INPE and 04 from EMBRAPA, which share the same resources. This research was based on an ongoing project that incorporates about 28 workers from both institutes to observe the Brazilian Legal Amazon.

\section{B. Requirements Elicitation}

The requirements definition is an early step, but at the same time it is continuous and critical in a system development, and refers to all aspects that involve the learning and understanding the users' necessities. It aims to elicit the user needs to the system developers. An important effort at this step is dedicated to uncover, extract and analyze the potential stakeholders. This process contains a group of

${ }^{2} \mathrm{http} / / / \mathrm{www}$.inpe.br/ingles/

${ }^{3} \mathrm{http} / / / \mathrm{www}$.embrapa.br/english 
activities that should allow the communication, prioritization, negotiation and all users' cooperation, beyond offers solid foundation to perform this complex and interactive process[14]. Elicitation is influenced by a large amount of factors and their multidisciplinary natures (concepts of creating and inventing requirements have been used to emphasize what really goes on during the elicitation) increase its complexity.

Often, the process starts with the definition of a mission for the project, at this time in a high level and incomplete way. It can be represented by a set of fundamental objectives, functions and constraints to the final system, or can be an explanation about the problems to be solved. To elaborate this description, stakeholders and a lot of other sources are identified and used with experts elicitation tools. These primary results provide the foundation for a deep and fine iterative and incremental investigation. The result is an amount of requirements wrote in natural language with simple diagrams, containing additional information (as sources identification) and priorities.

The elicited requirements should be validated observing other stakeholders and systems, at then make a comparison with early system objectives. Based on [14], [15], it was made a summary of techniques to requirement subtraction that will be used at this work.

Interview: The interview is a commonly employed method to the requirements elicitation. Here the analysts identify and discusses the different kind of stakeholders to understand the necessities and the targets to be reached by the system. This method is an efficient way to collect large amounts of data quickly, and its results can vary significantly depending on the skill of the interviewer. Typically, there are mainly three types of interview:

- Structured interview: Some predefined questions are formulated, in order to extract specific answers, to gather specific information.

- Unstructured interview: There are not predefined questions, thus, the information is gathered in open discussions focused on identify the expectations of the stakeholders about the system.

- Semi-structured interview: Being a combination of the other two, some predefined questions are formulated more to stimulate the discussion about the system than to extract information as in a structured way.

Structured techniques are directly related to the interviewer knowledge to elaborate the right questions to gather the right answers from the right people. Unstructured interview takes the risk that some topics may be neglected, or that the discussion be focused on gather a lot of specific details of one topic whilst gather not enough details about other one.

Introspection: This technique requires the development of requirements based on what the analyst believes that are the demands and necessities of the system users and stakeholders. It represents an initial point for other requirements elicitation approaches and it is really effective when the reporter is at the same time familiar with the system goals and domain, and is familiar or even expert in the business processes performed by the users.

Scenarios: It is a widely used technique based on narratives and specific descriptions of the process (current and future), including actions and interactions between users and the system. Scenarios do not consider the internal system structure, which requires an incremental and interactive method to their development. It is important to note that when using scenarios, all the potential exceptions for each step should be gathered.

\section{Techniques Implementation}

The interview was realized in an unstructured way, in which one topic starts the discussion by a question and its answers, amplifying the perception about that topic as well as its understanding about the problem by all participants, the analyst and users.

The introspection could be made once the analyst had knowledge enough about the studied system as well as the focused area, TerraAmazon and GIS respectively. Thus, it was elaborated some relevant questions considering the GIS behavior and the way to work of the users. At sequence follows the main questions made:

- How long you use the TerraAmazon?

- What is/are the function(s) that you assume on TerraAmazon?

- There is some kind of interaction among users about the operations to be made?

- If there is interaction, it occurs in TerraAmazon interface or it is external, by e-mail, for example?

- There is required real-time message/information exchange among users during system operation?

- How often there is interaction among users from different locations in TerraAmazon projects?

- The activities have synchronous behavior, i.e. one user needs one task to be finished by another user to begin his/her?

- There is some planning, organization or control of which activities should be accomplished and by whom?

Within interview was discussed a lot of scenarios using the TerraAmazon, it can be highlighted:

- Interaction among users classifying several cells of one same region at the same time, locally or remotely;

- Communication among different system users when doubts or some problem related to georeferencing of an area occurs;

- Two users trying to use one same cell to classify it.

During the interview and discussions, the client shows the operation of each topic discussed in real-time, which has facilitated the understanding of real requirements inside institutions.

\section{RESUlTS AND DisCUSSION}

This section aims to present the relevant features of the current system and the requisites gathered by requirements elicitation methods, and finally, make the validation and the proposal to the requirements implementation based on CSCW concepts.

\section{A. System Operation}

The TerraAmazon project is basically summarized by the following steps:

1) Image Import: The interested satellite image is loaded to work at the GIS interface;

2) Georeferencing: The pixels of the imported image are mapped to geographical coordinates on real world; 
3) Linear Spectral Mixture Models: This technique is applied to image to emphasize specific features. For example, one can desire to stress the feature of undergrowth.

4) Segmentation:The image is partitioned on polygons with similar features to each other.

5) Classification: Automatically, for each polygon is designed one class (water, undergrowth, forest) according its features - texture, color and so on;

6) Interpretation and Edition: The automatic classification represent a starter process for the final classification, when from this point one should validate the classified polygons or suggest another label, by editing function. One can also manipulate the polygons in order to aggregate adjacent regions.

The result interpretation and possible editions are made in a concurrent way by several users, for this purpose the cells are distinguished by colors (green, red or uncolored) outlining one specific area to the user. One cell with no colored border indicates that the cell is available for edition; with a green border, the cell is on editing by the local user, which represents a cell with red border to other users. The analyst can make the cell available for editing by another one during his/her edition (the Fig. 1 can be consulted to illustrate this occurrences).

7) Auditing: The classified areas are submitted to an auditor, who is responsible for checking the classification consistency, confirming it or not. If it is not confirmed, the auditor denies the classification exposing their motivation, beyond indicates the guidelines for correct classification, causing the interpreter to return to the previous process.

8) Propagation: When the classification process is finished, the map is completely formed, georeferenced and saved on database, then its information can be reached by all user for each particular projects.

The Fig. 2 shows the TerraAmazon processes flowchart.

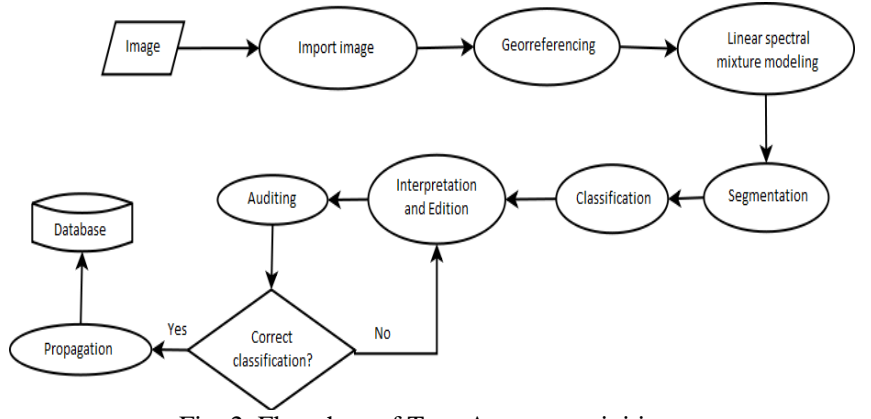

Fig. 2. Flowchart of TerraAmazon activities.

\section{B. Requirements Elicitation}

Based on interviews were defined three main requisites to TerraAmazon: an internal message exchange module, a coordination module and a structure to be shared among co-workers in a project. These requirements are clearlyin accordance with four of the five applications classes described in [3]: Awareness support, Communication support, Coordination support and Team support.

There is not a module to interaction among users within TerraAmazon. Thus if the user 'A' has one doubt about one cell classification he/sheestablishes contact by external messages or even personally with the task responsible. There is a module to message exchange on database management system but is a not practical solution, e-mail or instantaneous messages are faster than that. A practical module to users' communication is a consolidated requirement.

Some projects could include different institutions in its execution, apart located (in a town or country), but actually, the system have not support for this type of project. As INPE-CRA has joint project with EMBRAPA, for example, it is necessary that the employees work at the same location (one of them building). Thus, there is a huge necessity of an integration module in TerraAmazon that allows different institutions to work over the same project without being in a same place.

There is not a module to support the organization, coordination and even to define the activities for each person involved in one project on TerraAmazon. Therefore, its designation is made in a spreadsheet or other external interface. This could be practical if doubts do not appear, but if one user wants to know specific information about one cell (already classified by another user), the person should consult the spreadsheet to discover who manipulated that cell and then contacting the responsible.

In another occasion, mainly in synchronous projects, one should wait for the finishing of a process to start other task. The final information must be entered in the spreadsheet for the knowledge of all, which can be very inefficient because spreadsheets don't emit alarms to the main system; there isn't integration between the platforms. There should be a module for project management. This module will be responsible to emit refresh alerts about the procedures designated and finished.

\section{Requirements Validation According CSCW}

The necessity of one module for exchange message requires the implementation of a Communicator system support [3], [16] as well as the implemented in [17]. Basically, this system is composed by groupware tools in which the main function is related to the aspects for users' communication. Within this context, it is important to develop more than a simple module of exchange message by instant messages tools (awareness support), but must to be a module for audio or even video conferences for important situations, as a meeting with all interested people (communication support). For more complex situations, as when the meeting should be personally, this interaction requires awareness, for example, when one analyst wants to know if his/her coworker is in his office before going there.

The requirements for shared work between institutions (INPE and EMBRAPA) defined by stakeholders could not be validated due INPE internal policies. The INPE networks involve Brazilian government confidential information and allow access to INPE databases could represent a breach of information security. But in other kind of co-work the team supports may also be required, without having security restrictions, then a module that implements this support can be implemented without compromising the access control restrictions. One example is the Cobricks (Bricks for Supporting Collaboration in Teams and Communities), a modular community platform toolkit that supports building and operating interoperable community platforms [18] [19].

Lastly, the organization by spreadsheet must be replaced by a Coordinator system [16] that contains a set of tools related to the temporal evolution of the project, ensuring that 
the activities be executed one after other in a sequence, solving problems related to synchronous activities. Beyond activities flow, the organizational aspect and of production is optimized in execution planning and in tasks allocation. Important to point out that, the coordinator must be linked to the cells information in order to be able to tell who edited it, the deadline to one processing, and so on.

The validated requirements are showed in use case diagram in Fig. 3.

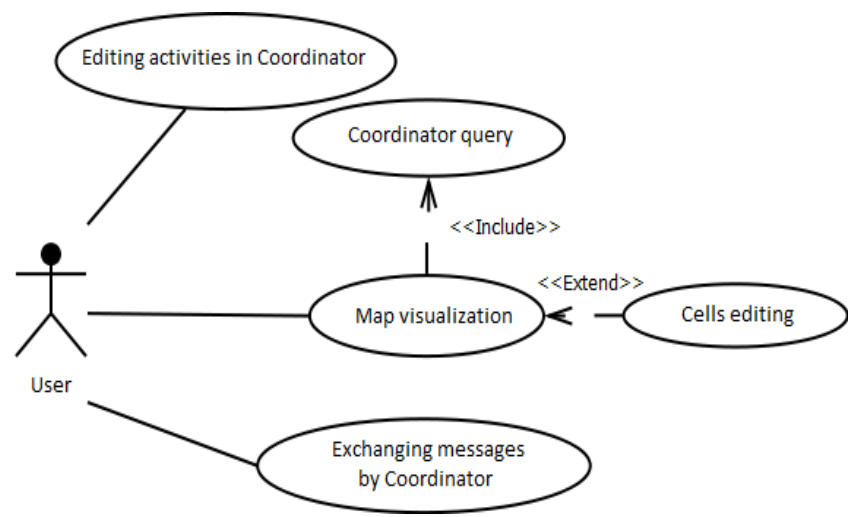

Fig. 3. Use case diagram of validated requirements.

\section{CONCLUSIONS}

GIS likely incorporates CSCW concepts by its comprehensive about social interaction, supporting the design, development and evaluation of the systems that support group projects.

This article shows some strategies based on CSCW, using groupware to feed requirements systematically collected, mainly through interviews about TerraAmazon, a GIS capable to perform spatial operations in a multiuser and concurrent interface which is used in a most important agency for remote sensing questions inside Brazil.

Through an unstructured interview have been identified three important requirements that are in line with a functional classification for discussing groupware: the need for a messaging module (awareness and communication support); an integration module to aggregate participants from different locations (team support), and; a module to support the organization and coordination of the project (coordination support). Due INPE internal policies, the second requirement was not validated, whereas was proposed a Communicator system to compose the first required module and one Coordinator system to supply the third necessity. Although not validated, was proposed a module for team support, to ensure that other users share their information (when security restrictions do not apply).

To future works, aims to do the development of groupware and one evaluation of its results taking in account the impact offered for the work group at that institution.

\section{ACKNOWLEDGMENT}

The authors thank the INPE and EMBRAPA researchers which contributed to realize this work.

\section{REFERENCES}

[1] K. E. Foote and M. Lynch, Geographic information systems as an integrating technology: Context, concepts, and definitions, Colorado: University of Colorado at Boulder, 2009.
[2] G. Fitzpatrick and G. Ellingsen, "A Review of 25 Years of CSCW Research in Healthcare: Contributions, Challenges and Future Agendas," Computer Supported Cooperative Work (CSCW)-The Journal of Collaborative Computing and Work Practices, vol. 22, pp 609-665, 1 August 2013.

[3] M. Koch and T. Gross, "Computer-Supported Cooperative WorkConcepts and Trends," presented at 11th Conf. Of the Association Information and Management(AIM), 2006.

[4] B. W. Luscombe and T. T. Poiker, "Strabo - an alternative GIS approach to decision makein for planning applications in data scarce environments," presented at 6th International Symposium on Automated Cartography-American Congress on Surveying and Mapping, 1983.

[5] N. Churcher and C. Churcher, "Grouparc-a collaborative approach to GIS," presented at 8th Colloquium of the Spatial Information Research Centre, 1996.

[6] N. Churcher, P. Prachuabmoh, and C. Churcher, "Visualisation techniques for collaborative GIS browsers," presented at Second annual conference of GeoComputation, 1997.

[7] B. Faber, W. Wallace, and H. Sargent, "Use of groupware-enabled gis for land resource allocation issues," presented at the 6th International Symposium on System Analysis and Management Decisions in Forestry, 1994

[8] J. Roth and C. Unger, "Dreamteam-a platform for synchronous collaborative applications," presented at Groupware und organisatorische Innovation: Tagungsband der Deutschen Fachtagung zu Computer Supported Cooperative Work, 1998

[9] V. Popovich, A. V. Pankin, M. N. Voronin, and L. A. Sokolova, "Intelligent situation awareness on a GIS basis," presented at Military Communications Conference, 2006.

[10] Y. Tsai, Z. Hu, and P. Siplon, "Gis-enabled maritime awareness system (gmas)," presented at IEEE Conference on Technologies for Homeland Security, 2009.

[11] A. Qureshi, M. Butt, and O. M. Khan, "The role of gis and public awareness for disaster management," presented at International Conference on Advances in Space Technologies, 2006.

[12] G. Câmara et al., "TerraLib: Technology in Support of GIS Innovation," presented at II Brazilian Symposium on geoinformatics, 2000.

[13] C. Diniz, U. L. S. Guimares, A. Gomes, and C. de Almeida, "Monitoramento de florestas tropicais utilizando sistema TerraAmazon-estudo de caso: Costa oeste do Gabão, África central," presented at Simpósio Brasileiro de Sensoriamento Remoto, 2011.

[14] D. Zowghi and C. Coulin, "Requirements Elicitation: A Survey of Techniques, Approaches, and Tools," Engineering and Managing Software Requirements, 2005.

[15] S. Gunda, Requirements engineering: elicitation techniques, University West, Department of Technology, Mathematics and Computer Science, 2008

[16] C. Ellis and J. Wainer, "Groupware and computer supported cooperative work," Multiagent systems, MIT Press, 1999, pp. 425-457.

[17] M. Handel, "What is chat doing in the workplace," presented at ACM Conference on computer supported cooperative work, 2002.

[18] M. Koch, "Community Support in Universities - The Drehscheibe Project," presented at International Confference on Communities and Technologies, 2002

[19] M. Kock. (27 Sep. 2013). Technische Universität München. [Online]. Available: http://www.cobricks.de/index.html

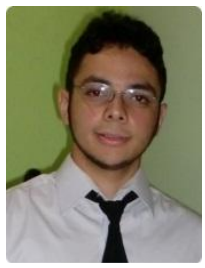

Danilo Sousa received his B.S. degree in computer engineering from Federal University of Para, Belem, Brazil, in 2011. He is currently a MSC. Student in the Post-Graduate Program in Electrical Engineering. His research interests are in digital image processing (image restoration, in painting, segmentation and classification), remote sensing and Pattern Recognition.

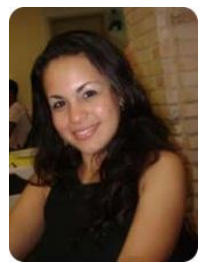

Ana Carolina Siravenha received her B.S. degree in computer engineering from Federal University of Para (2008) and the MSC degree in electrical engineering from the Federal University of Para (2010). She is currently a $\mathrm{Ph} . \mathrm{D}$. student in electrical engineering at the Federal University of Para. She has experience in Electrical and Computer Engineering with emphasis in signal processing, mainly in the following areas: digital image processing, remote sensory images segmentation and classification, image restoration and Discrete Cosine Transform applied to classification. 


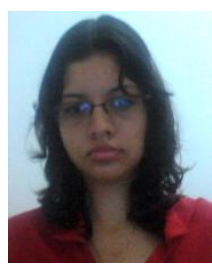

Damares de Resende was born in Para, Brazil on October 25, 1992. She is currently a undergraduate in computer engineering from the Federal University of Para and is linked to the Institutional Program for Scientific Initiation Scholarship, working as a programmer in the Laboratory of Signal Processing (LaPS) in the area of Remote Sensory and Digital Image Processing (DIP). Her research interest includes DIP, algorithm analysis, database and genetic algorithms.

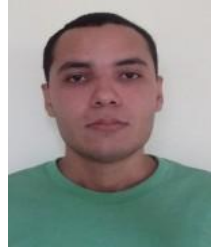

Reginaldo C. S. Filho was born in Para, Brazil on October 18, 1988. She graduated in computer networks at the Faculty of Amazon Technology, Pará, Brazil in 2008. He is currently majoring in computer science from the Federal University of Para and is linked to the Institutional Program for Scientific Initiation Scholarship, working as a programmer in the Laboratory of Signal Processing (LaPS) in the area of digital image processing (DIP). His research interest includes PDI, computer networks, desktop, web and mobile developing, defensive programming, algorithm analysis, database and genetic algorithms.

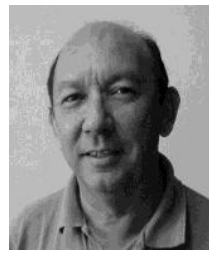

Evaldo Pelaes received his B.S. degree in electrical engineering from Federal University of Para (1977), ful undergraduate degree in physics from the Federal University of Para (1977), MSC. degree in electrical engineering from the Catholic University of Rio de Janeiro (1982) and Ph.D. in Electrical Engineering State University of Campinas (1998). He's currently an associate professor at the Federal University of Para and has experience in electrical engineering with emphasis in signal processing, mainly in the following areas: wavelet transform, image coding, propagation models, and mobile power quality. 